\title{
Exploring a new era of screen production research: Laying foundations for engagement and impact
}

\author{
Craig Batty
}

School of Communication, University of Technology Sydney, Sydney, Australia

\author{
Marsha Berry
}

School of Media and Communication, RMIT University, Melbourne, Australia

Bettina Frankham (corresponding author)

School of Communication, University of Technology Sydney, Sydney, Australia

Faculty of Arts and Social Sciences, University of Technology Sydney

PO Box 123 Broadway NSW 2007 Australia

email: bettina.frankham@uts.edu.au

Professor Craig Batty is Head of Creative Writing at the University of Technology Sydney, formerly based at RMIT University. He is author of over 50 books, chapters, journal articles and refereed conference proceedings; editor of two books and 10 journal special issues; and has worked as a writer and script editor on various film/screen projects. He is currently Chair of the ASPERA Research Sub-Committee. In 2016 he received an AAUT Citation award for his contributions to excellent HDR outcomes in creative writing, and also won the inaugural RMIT Research Award for Innovative Research Supervision. His current areas of research are script development practices in the screen industry, and doctoral education in creative practice disciplines. Craig is also Adjunct Professor at Central Queensland University, and Visiting Research Fellow at the UK's Bournemouth University.

Dr Marsha Berry is Senior Lecturer in the School of Media and Communication. She is author of Creating with Mobile Media (2017) and co-editor of two books, Mobile Media Making in an Age of Smartphones (2014) and Mobile Story Making in an Age of Smartphones (2018), Palgrave MacMillan. She has published her research extensively in international journals such as New Media and Society and New Writing, as well as in edited books. She is an ethnographer, writer and artist whose practice includes filmmaking, participatory art projects, and poetry. Her video art has been exhibited at prestigious venues including the Director's Lounge in Berlin, 
Queensland Centre for Photography, Brisbane, Australia and VM Art Gallery, Rangoonwala Community Centre, Karachi, Pakistan. She is a member of the ASPERA Research SubCommittee.

Dr Bettina Frankham is a practice-led researcher in digital media. She has a background of industry experience that spans television, radio and online production. As a moving image practitioner, she makes creative media that works across documentary, art and poetry. Her projects have screened at international media arts festivals including Videobrasil International Electronic Art Festival, Stuttgart Filmwinter Festival for Expanded Media, Berlin Asia-Pacific Film Festival, the Artivist Film Festival California and Flickerfest International Short Film Festival Australia. Her research interests include expanded documentary practice and the impact of digital culture on creative media production. She is currently exploring the role of aesthetics in knowledge creation and the shift in documentary to a rhetoric of experience. Bettina teaches in media arts and production in the Faculty of Arts and Social Sciences, UTS. She is the current Vice-President of ASPERA and a member of the ASPERA Research Sub-Committee. 


\title{
Exploring a new era of screen production research: Laying foundations for engagement and impact
}

\author{
While the discipline of screen production is firmly getting to grips with what it \\ means to research about, for and with the screen, a new research challenge \\ emerges: how to see this research as engaging with those beyond the academy, \\ and having impact. In many ways, the idea of engagement and impact should be \\ easy for screen production, given the nature of its form, audience and intent; but \\ it is not so easy when we put research into the mix. For example, what is the \\ relationship between research and engagement? How can impact be measured in \\ relation to research intentions and contribution? Will the desire for impact change \\ the very nature of screen production research, and/or will it only be seen as a \\ 'service provider' for other disciplines? \\ Written from the perspective of the peak body for screen production education \\ and research in Australia (ASPERA), but referring to international contexts and \\ case studies, this paper draws from a research symposium held in 2017 that \\ purposely brought together academy and industry to explore strategies for leading \\ on the engagement and impact agenda. It explores what engagement looks like \\ and how it can be structured as a pathway to impact; the implications and \\ mechanisms for measuring impact in a variety of contexts; and the possible \\ ramifications of the engagement and impact agenda on the nature of a \\ practitioner-researcher's work. The paper thus provides a set of complex and \\ competing perspectives that, while on the one hand provide principles and \\ models for best practice, on the other hand question and problematise this new \\ era of research.
}

Keywords: screen production research; engagement and impact; industry; research practices; research training

\section{Introduction}

Following a period of research consolidation in 2015 and 2016, which saw the publication of over 50 journal articles and refereed conference proceedings from the Australian Screen Production Education and Research Association (ASPERA) community, 2017 saw ASPERA further develop its capacity for disciplinary research 
with a view to securing its future as an internationally recognised practitioner-researcher peak body. As well as more journal articles from it members, edited collections were also published and contracted. Screen Production Research Reporting: An ASPERA Scoping Project was also launched (ASPERA 2017), which sought to capture some of the long-standing discussions and issues the discipline was facing regarding creative practice research reporting and evaluation. A further question, 'What does quality look like in a screen production research artefact?', arose, and a set of guidelines for addressing this is in preparation.

No sooner had ASPERA ‘caught up' with other disciplines than another research issue arose: engagement and impact. Driven by the Australian Government as part of its National Innovation and Science Agenda (NISA), researchers and research managers across Australia have been tasked to improve upon the levels of engagement taking place between researchers and non-academic end users, and further, to evaluate the impact that university research is having on the wider culture, economy, environment and society. To be part of these conversations across universities through knowledgeable academics, ASPERA devised a one-day research event in the form of a symposium, to discuss this new research agenda and tease out some of the implications for the screen production community.

The 'Screen Production Research Engagement and Impact Symposium' (SPREIS) was held at the University of Technology Sydney (UTS), and comprised a keynote address from the University of Canberra's Distinguished Professor Jen Webb (see Webb 2017), and three discussion panels with participants from both academia and industry, including those from National Indigenous Television (NITV), Special Broadcasting Service (SBS), the Museum of Applied Arts and Sciences and Screen 
Australia. There were 56 registered participants from the ASPERA community and beyond, including $\mathrm{PhD}$ candidates, in attendance and contributing to the discussions.

The purpose of the event was twofold. Firstly, gather data on how academics in the screen production discipline are understanding and responding to the requirements of engagement and impact reporting for analysis; and secondly, share the insights gained with members of the ASPERA community and representatives from related industry organisations. The symposium was carefully designed to address our research questions concerning the implications of the new engagement and impact research agendas for the research conducted by members within the ASPERA community. All attendees were made aware of the research component that was built into the structure of the symposium with participant information sheets and consent forms made available to all participants, both online during registration prior to the event and via hard copy at the venue on the day. Our research questions were: What is the relationship between research and engagement? How can impact be measured in relation to research intentions and contribution? Will the desire for impact change the nature of screen production research, and/or will it only be seen as a 'service provider' for other disciplines?

We wanted to better understand how academics and those in industry saw this shift in the national research agenda, and so we invited key researchers and industry practitioners to discuss their interpretations of engagement and impact, focussing on research in the creative arts generally, and screen production in particular. As a research project, human ethics for gathering qualitative data, similar in format to a focus group, were approved by UTS and all those referred to below gave their permission to be quoted (anonymously). The project was also registered at RMIT University as two of the researchers were at RMIT at the time. The panelists participating in the symposium 
were identified as the key participants contributing data to the research project with opportunities for members of the audience to also make contributions.

In this article, we consider the key themes that arose from the research symposium in response to our research questions, and the implications they might have for the screen production discipline in order to analyse the state of the field at this point in the roll out of the engagement and impact reporting regime. These themes include the significance for screen production research of having the domain of culture added to the areas of potential impact within the ARC definitions, the generative power of blue sky and passion driven research due to the industry connections of many screen production academics, and what can be described as the invisibility of creative practice research within industry conceptions of what constitutes academic research. We begin by laying out the context for research engagement and impact, and then provide an overview of some of the relevant existing literature. We then turn to analysing the themes that emerged from the three panels in response to our prompt questions, including a discussion of what this might mean for the discipline. Lastly, we present a series of implications that this new climate of research has for the screen production discipline broadly, and the ASPERA community specifically.

\section{Context: The engagement and impact assessment pilot}

In 2015, the Australian Government commissioned Dr Ian Watt AO to conduct a review of research policy and funding in Australia. Subsequently referred to as the Watt Review (2015), this report was strident in its criticism of the lack of end-user (namely industry) engagement with and impact from university research, especially in comparison to other OECD countries. It called for better mechanisms to encourage, facilitate and evaluate research collaboration with industry and other end users, including funding models that would incentivise such work and different approaches to 
research training. In short, the Watt Review recommended the following be undertaken by the Government as soon as possible: ensure the quality and excellence of Australian university research and research training; allocate funding through Research Block Grants $(\mathrm{RBG})$ in a simpler and more transparent manner; provide incentives to universities to increase and improve engagement and collaboration with business and other end-users; encourage universities to engage in research commercialisation and knowledge transfer with business and the broader community, including through funding incentives and a focus on more effective management of intellectual property (IP); and ensure that competitive grant criteria recognise the quality of the proposal and support the opportunities for commercialisation and collaboration with business (Watt 2015).

As highlighted by Distinguished Professor Jen Webb during her SPREIS keynote, which addressed the significance of the engagement and impact agenda and its implications for the creative arts, what this emerging agenda really all comes down to is the perceived 'relevance gap' (Webb 2017) of academic research. In short, if the Government is investing billions of dollars in research each year, what is the value for those outside of the academy? Is this a good investment of public money? A similar notion was reported in the Journal of Media Practice following the UK's 2014 Research Excellence Framework (REF) - which for the first time reported on, and then directly funded universities on the basis of, an assessment of research impact - where impact was flagged as 'the manifestation of "value for money" for academic research' (Adams and McDougall 2015, p. 97).

During 2017, the Australian Research Council (ARC) conducted a pilot for assessing engagement and impact across Australian universities, with a view to developing a robust methodology that would then be fully implemented within the 2018 
Excellence in Research for Australia (ERA) audit. The pilot exercise only assessed the engagement and impact achievements of a small number of Field of Research (FoR) Codes, namely: for engagement, 03 (Chemical Sciences), 11 (Medical and Health Sciences), 21 (History and Archaeology) and 22 (Philosophy and Religious Studies); and for impact, 05 (Environmental Sciences), 07 (Agricultural and Veterinary Sciences), 09 (Engineering), 13 (Education), 19 (Studies in Creative Arts and Writing) and 20 (Language, Communication and Culture). In addition, universities were able to submit case studies for impact assessment of institutional interdisciplinary research and Indigenous research. Across all assessments, submissions were given a rating of 'mature', 'emerging' or 'limited'. Anecdotally, there were a number of case studies submitted from members of the ASPERA community for FoR Codes 19 and 20. This is a positive sign that some of its researchers are already involved in the new agenda; though as will be discussed, to what extent and making which types of knowledge contribution is still up for debate.

The ARC report emerging from this pilot states that it 'represents an important step towards recognising the research achievements universities make in addition to research excellence' (2017, p. i), which - as per Webb (above) - places an interesting focus on the purpose of research: being 'excellent' is one thing, but what does that mean beyond the academy? As the ARC's CEO notes in the report, the full engagement and impact assessment in 2018 should 'succeed in identifying the valuable engagement activities the sector undertakes and the resulting impact its research makes to our society, economy, environment and culture' (Australian Research Council 2017, p. i). It is important to note here that the word 'culture' was not named in the pilot guidelines, but was added to them from 2018 as a result of much feedback from assessors, presumably those in FoR Codes 19, 20, 21 and 22, for whom culture is an important 
'end user' of research. Given that the nature of most of the work of the ASPERA community tends to focus on aspects such as providing public information and entertainment, questioning societal norms and capturing and representing the human experience, this is seen as a welcome development.

\section{Defining engagement and impact}

Based on the 2017 engagement and impact trial, the ARC altered some of its definitions and measurement tools for the full assessment in 2018. Here we use those new definitions and tools (Australian Research Council 2017, pp. 2-3) as the basis for discussion, which also serves to highlight to readers the specific parameters of what we are exploring. Accordingly:

The definition of engagement was simplified to:

The interaction between researchers and research end-users outside of academia, for the mutually beneficial transfer of knowledge, technologies, methods or resources.

End-user is explicitly defined as:

An individual, community or organisation external to academia that will directly use or directly benefit from the output, outcome or result of the research.

Examples of end-users include businesses, governments, non-governmental organisations, communities and community organisations. Specific exclusions of research end-user are:

Publicly funded research organisations (e.g., CSIRO, AIMS, ANSTO).

Other higher education providers.

Organisations that are affiliates, controlled entities or subsidiaries (such as Medical Research Institutes) of a higher education provider. 
The definition of impact was refined to:

The contribution that research makes to the economy, society, environment and culture beyond the contribution to academic research.

Regarding the methodology for assessing engagement, modifications were made so that the four quantitative indicators for collection and assessment are:

(1) Cash support from end-users (against Higher Education Research Data Collection (HERDC) categories).

(2) Total HERDC income per FTE (specified schemes).

(3) End-user sponsored grants: proportion of HERDC Category 1.

(4) Research commercialisation income.

Of further interest, during the 2018 assessment data on the co-supervision of Higher Degree by Research students by end-users will be collected, though not assessed. The ARC expects that future rounds will assess this indicator.

\section{Mapping extant ideas of engagement and impact}

While ideas of engagement and impact are only recently circulating within the academy - though many would argue that they have been doing it for years anyway, perhaps just not under those precise definitions and without the formal Government-driven conditions - there are many areas where such concepts are inherently built into a project. (Of perhaps ironic note here is that it was the now-defunct Australian Office for Learning and Teaching (OLT) that first formalised research engagement and impact, though its secondment of Tilly Hinton to develop the 'IMPEL' framework for learning and teaching scholarship (see Hinton 2014). 
For example, many practitioners see themselves as engaging with 'end users' from the early stages of a project, especially in participatory areas such as community theatre and media and communication for development. Linje Manyozo, for example, argues for a 'pedagogy of listening' to end users within communication for development projects, because

curating development with and alongside communities is fundamental to deliberative development, which opens up pathways for imagining possibilities of social change whose seeds will be sown when oppressed individuals and groups learn to accept that their current situation is unacceptable; that positive change itself, even the very idea of it, is revolutionary and confrontational in nature (2017, p. 28).

Writers and filmmakers working in the realm of education or social justice, too, would not only see themselves as engaging with their audiences with a deliberate ‘educative' agenda (see Barton 2017; Beker 2013), but might also have developed frameworks for mapping and evaluating impact during the project's development. It would, for example, be normal practice for arts-based organisations to create evaluation frameworks for new policies, programs and performances, to name just a few (see, for example, Galloway 2009).

Chatto and Das (2014), from the Center for Media and Social Impact at the American University, Washington DC, prepared a white paper to deal with the challenges of examining and measuring the social impact of storytelling. Social impact for them is defined in the following ways $(2014$, p.7):

- Social impact is a broad umbrella concept that can include change to individuals, groups, systems and institutions.

- Social impact in this particular context does not include financial measures of success, which are evaluated distinctly. 
- Social impact assumes a public interest foundation - an improvement of a state of affairs around a social issue.

Chatto and Das argue that it is 'crucial to begin with a shared language and understanding about how impact evaluation can fit in the cycle of work, and how to ensure it is optimally useful' $(2014, p .4)$. They point out that there is no specific recipe to examine and evaluate impact; rather, they propose that existing social science research methods are a promising way to measure and evaluate impact - at least as a starting point. Similarly, Tracey Friesen (2014) conducted research for the Inspirit Foundation into the impact of documentary films, and found that:

Long-form films, with authentic and compelling stories, can alter people's perceptions and move them to behave differently. From qualitative and anecdotal reports, we learn of viewers' lives being transformed because of their exposure to new worlds or ideas. Because of more recent quantitative approaches, we now have data to see how these emotional responses translate into actions - such as discussing the topic with others, signing petitions, and donating to causes. These cumulative actions can lead to legislative change and an overall societal mindset shift (Friesen 2014, p. 3).

While some might see this new era of planning and evaluating engagement and impact as scary, if not a capitalistic and anti-intellectual pursuit, for others who do this type of work anyway, there are opportunities for diversifying the nature and fabric of an academic department's research footprint. The Journal of Media Practice, for example, reports that during debrief meeting post the $2014 \mathrm{REF}$, an strong feeling was that 'the over-production and commodification of research [...] is set against, depending on one's political view of research and institutional background, the more inclusive effect many people working in newer universities are afforded more time and space for research because the REF exists' (Adams and McDougall 2015, pp. 97-8). In other 
words, if research evaluation exercises exist then universities must recognise this in the workloads of their academics. Might the same then be said for engagement and impact? Will those researchers with clear engagement and impact plans, if not prior industrybased experience in the area, be rewarded with more time to undertake this (now) crucial work? Further, might roles for research leadership exist for those who might not traditionally have been considered 'worthy'?

On REF impact scores specifically, the following key points are raised from a media practice perspective (Adams and McDougall 2015, p. 100):

Sub-panel 34 [Art and Design: History, Practice and Theory] makes an important point about how festivals and exhibitions should be shown to relate to the impact of the underpinning research. Sub-panel 35 [Music, Drama, Dance and Performing Arts] provides a constructive critique of the presentation of relations between research and public engagement, observing that some submissions, despite evidently strong relations across the relevant cultural industries, did not fully capitalise on the potential of the impact embedded in the research practice culture.

A characteristic criticism of the impact statements came from sub-panel 36 [Communication, Cultural and Media Studies, Library and Information Management], who identified the need to show how dissemination led to impact, and the underpinning research led to benefits for identified users. Without apparent irony, it notes that there was some confusion between 'impact, knowledge transfer and dissemination'. This emphasises the need to take a systematic approach to presentation, with a clear understanding of terminology and categories.

At several points the validity of a local geographic focus is noted. Sub-panel 34 emphasised that localism is not an impediment to international relevance: 'a significant number of case studies based in specific regions ... presented outstanding and very considerable impact'. Sub-panel 36 identified a 'sensitive and creative range of work on regional and local issues through a variety of media formats'.

This raises important notions such as definitions of impact (i.e., in contrast to dissemination (publication/presentation) and knowledge transfer (engagement); 'pathways to impact' (i.e., can the impact be traced through a series of engagement 
activities?); estimating impact (i.e., being aware of how it might evolve from a research project); and breadth and depth of impact (i.e., international impact is not necessarily more important than local impact). For us here in Australia, there is clearly a lot to still unpack and agree upon - even if the ARC's definitions of engagement and impact are transparent - particularly from a disciplinary context.

With all of this in mind, the 2017 symposium hosted by ASPERA sought to unpack some of the current thinking around engagement and impact - primarily to bring the ASPERA community up to speed - and to tease out some of the ways in which the discipline of screen production might work within this new research agenda, one arguably more about research as an economic driver than an intellectual pursuit (see Webb 2017). The symposium was as much exploratory as it was pedagogic, and in the spirit of open-mindedness and collegiality, was very much framed not as 'how to do a good piece of engagement and how to get good impact rating', but rather, 'what are the guiding principles and practices that we can engage with in order to think about the research we do?' (See Webb 2017).

Engagement and impact operate in much the same way across all disciplines, and so through the symposium we sought the views and experiences of not only those with direct links to screen production, but also those with broader research and leadership experiences who might help us to translate current policy on behalf of and for the ASPERA community. In the following section we examine the three key panel discussions that took place at the symposium: one with industry representatives; one with academics; and one with research leaders. The panel discussions were audiorecorded, and while some of these speakers were happy to be named in this article, others preferred not to be, or not to have named the specific examples of research projects that they gave. To this end, and for the sake of consistency, we have 
anonymised all the discussions - except to identify the panel membership type - and provided summaries of the key ideas and issues raised by the panels, along with our own analyses of what was presented. (The contributions of one panelist who declined permission to be included were redacted from the audio recordings of the event.) Following these summaries, we reflect on what all of this might mean for the screen production sector broadly, and the ASPERA community specifically.

\section{Perspectives from industry}

The industry panel comprised people working in leadership or research roles within organisations that incorporate screen production as part of their operations. The focus on screen production ranged from broadcasters whose primary objective was the production and distribution of screen content, through to curators from the GLAM (galleries, libraries, archives and museums) sector that incorporated moving image content into their exhibitions. Some of the panellists had been actively involved in academic research projects, while others had direct experience with developing knowledge exchange plans and amplifying the impact of content developed by their organisation. They were asked to give examples of research projects they had undertaken, offering insights as to what had worked well and not so well. They were also asked to outline types of research problem that would be of interest to them, and discuss the ways they would like to work with universities on these problems. Examples of research questions provided to the panel include:

- What is your understanding of the aim of the Government's National Innovation and Science Agenda (NISA)?

- How do you see NISA working in screen production and cultural industries?

- Has this agenda led to any changes within your organisation so far? 
- How would you conceptualise engagement and impact in the realm of screen production?

- What do cultural industries need to do to engage with this new agenda?

At the start of this panel session the participants were asked to talk about specific research projects they had been involved in that were either good or not so good models of research collaboration. The first speaker described the development of an animation series that responded to research undertaken by the Australian Council for Educational Research (ACER) into ways of transitioning Aboriginal and Torres Strait Islander children from kindergarten to school. The research specifically looked at television as a medium of making the school space more familiar and friendly to young children. The animation series was developed by the broadcaster in collaboration with ACER and resulted in 13 short animation episodes supported by a website with curriculum resources for schools and educators. While the key outcome focus of the research was to measure the impact for young Aboriginal and Torres Strait Islander children and how their transition pathways to school had improved, the collaboration has also resulted in a series that has been made for all children and is therefore of significant relevance for the agenda of reconciliation.

The next speaker outlined a project that established an interactive, screen-based exhibition space where artists could prototype their works. It was mainly postgraduate $\mathrm{PhD}$ students who used the space, and part of their undertaking in gaining access to the space for their work was that they had to conduct audience-based research on their works in that space. Over the 5 years during which the project was active, there were 33 different works installed into the space. Outcomes from the research included a strengthening of skills in audience evaluation for both the academic team and the institution hosting the works. Six people completed their PhDs and there were several 
scholarly publications, including two books that focused on the findings from the research project. The speaker stated that it was a mutually beneficial collaboration that allowed both groups to achieve their project goals. The project has proved to be very influential in how the institution has approached collaborations with academic groups since then.

This influence includes the need for a very clear statement around the difference between working in an academic research facility and working in a research space that is open to the public from the outset of a project. Within the context of a GLAM institution, where the space is open to the public, there are requirements that research work be undertaken during the opening hours of the institution. This requirement is because bringing the public into the 'experiment' of the space was a significant goal for the hosting institution. The speaker also highlighted an interesting tension where the academic researcher might see research interest in things "not working" but for a GLAM institution, that is partly set up to entertain the public, this is seen as a significant problem. The strategy that evolved was to make it clear to members of the public who visited the space that they were also part of the experiment. Members of the public were encouraged to recognise that with new technologies and experimental practices things may not always go according to plan, but that may be the prompt for new discoveries and connections being made.

As a practitioner who had worked within television broadcast organisations and more recently academia, the third panellist noted the necessity of addressing the usefulness of scholarly work outside the academy. He did, however, flag a danger in creating structures of funding and assessment that encourage the design of projects around what is measurable rather than other, more abstract, and therefore less measurable criteria. He gave examples of broadcast projects he had worked on that had 
produced a suite of differentiated creative responses that did not have an overt research question, but that retrospectively could be seen to be engaging with a question such as 'how might innovation in the television form contribute to healing under the rubric of reconciliation'? For this practitioner, engagement and impact is what the work of creative industries is already about. He expressed the idea that impact would be better understood as "in depth engagement ... that sees the citizen rather than consumer in its address". He also posed the question of whether there is an opportunity for scholarly engagement and impact with industry and culture through more focused dialogue at the level of work and practice.

The fourth panellist expressed a strong need to have a "safety net of academic research that underpins" their practice in developing content that extends broadcast materials for use in primary and high school classroom contexts. She saw a place for academic research to answer questions of whether the materials they produce are having the impact they hope to, and if the content is doing the things in classrooms they are saying it does. This extends to research that could evaluate the effectiveness of how their material engages with the Australian curriculum, to the degree of discerning whether and how the content they produce aligns with the syllabus outcome codes her organisation has identified as relevant (for example those set out by the NSW Education Standards Authority or NESA). She also expressed an interest in research that could engage directly with young learners to garner their feedback on the content that is produced by her organisation, rather than only hearing from the teaching level of users. She saw her role as a potential bridge into the collaborative research space between the academy and industry, as she already is involved in tailoring content for different forms of outreach and community engagement. 
The final panellist worked as part of a research team within a large, publicly funded screen industry organisation which produced its own research reports and is largely self-sufficient with regard to undertaking research projects. Their research work is focused on the quantifying of key aspects of screen industry culture, including participation rates of different groups as industry workers and the representation of minority groups within the content produced by the Australian screen industry. Their research also extends to the cultural impact of screen content. This research is at times conducted in collaboration with government institutions such as the Australian Bureau of Statistics.

It is interesting to note the gap between how some of the industry panel members conceived of what an academic research contribution might be, and the kind of practice-based research that members of the ASPERA community do. There was a sense that social science-, education- and audience studies-style research were perceived as the areas where academics could contribute, with little to no discussion of the kind of production research that is evident in the ASPERA-associated outputs that are available to date. This gap perhaps speaks to the immaturity of the screen production research discipline, and the level of visibility of its outputs within related industry fields. In terms of research that is directly relevant to an industry requiring quantification of the number of eyes it attracts to its outputs, the desire to understand their audience via audience research on the part of the industry panellists is completely understandable.

Other research disciplines, such as the social sciences and education, have put in considerable efforts over the past decades to show industry and broader society the relevance of what they do, through work in the social policy space and in establishing best practice for educators. It may now be that screen production research needs to engage in a similar process of planning for knowledge exchange beyond the academy 
when developing a research plan or proposal. There is a need for screen production researchers to show industry the value of creative practice research, and to assert that academics can add value for the creative industries in ways that go beyond traditional social science methods. Since members of the screen production discipline are themselves only just beginning to understand creative practice research as a methodology in its own right, it is not surprising that those outside of the discipline do not yet grasp what it can contribute.

Much of current screen production research within the ASPERA community is of the blue sky, passion project variety, as is evidenced in many of the abstracts of conference papers, submissions to conference proceedings and inclusions in the Sightlines journal that are available to view on the aspera.org.au website. The process frequently follows that described by Ross Gibson, where a screen production researcher has an inkling of something that would be interesting to explore, a creative project they would like to make, and they then gather the physical and theoretical resources required to realise the project so that the 'messy routines of creativity [are] oscillating with the distanced analytics of reflective critique and theorisation' (Gibson 2018, p. vi).

At an intuitive level at least, most screen production researchers are keyed into current industry developments. Consequently, the practices they are interested in investigating do tend to reflect current contexts and so are relevant, at the very least to the knowledge and experience that is required to be an effective tertiary educator in screen production.

While the jury is still out on whether there is any strategic advantage for screen production researchers to pursue engagement and impact, in the context of diminishing funding for the university sector and a push by some institutions to include external funding as an element of academic performance indicators, there may be value in taking 
a portfolio approach to research planning so that projects of direct relevance to industry and government policy are included alongside passion projects. However, this would mean that screen production researchers will need to gain additional research skills in areas such as statistical analysis, audience studies, education practice and so on. This may be a similar shift to what has occurred as screen production practitioners have had to acquire and develop scholarly writing skills to keep up with the requirements of their academic positions. But as with that occurrence, there remains a need for strategies that enable these screen production academics to: maintain the practice that gives them their unique perspective; nurture a strong sense of their discipline base; and develop confidence in sharing the benefits of their expertise more widely in the midst of the other demands of the 21 st century academy.

An alternative would be to identify, from the outset, research collaborators from the social science or education disciplines, for example, who can provide these skills with pre-existing experience in those methodologies. Such a strategy could prove to enact an effective reversal of the more common practice of structuring a research group, where the screen production researcher is brought on as adjunct in service of another research discipline.

\section{Perspectives from researchers}

This panel comprised members of ASPERA, who were selected because they are active researchers using creative practice methodologies as well as being lecturers in undergraduate and postgraduate programs in the area of screen production. They were asked to articulate their understandings of the new engagement and impact agenda and discuss the kinds of ideas already circulating at their respective institutions. They were also asked how this agenda was likely to affect their own research aspirations and goals. Examples of prompt questions provided to the panel include: 
- How are ideas of engagement and impact already circulating in your university?

- Do you feel your, or others', research behaviour will change - for better or for worse?

- What screen production work have you already done that you think would fit into the engagement and impact framework?

- Will the engagement and impact agenda enable you to develop ideas and partnerships that, in the past, have not been possible?

- What concerns do you have about the emphasis on engagement and/or impact?

- What opportunities do you see with this emphasis on engagement and/or impact?

When asked about the kinds of ideas of impact already circulating, one academic researcher on the panel felt that there is a distance between blue-sky research where impact pathways are not obvious, and more applied research that aims to change practice and/or approaches to practice and can been seen as impactful. The researcher observed that according to their institution, not all research has to be thought of in terms of impact, and this is a good thing. There was a consensus amongst the panel that impact is actually a long game, and one needs to be thinking about this from the outset and build it into the design of research projects.

Impact was also seen as something researchers build towards. One researcher observed that we should think about how to collect material that might be considered as evidence of impact further down the track, particularly for the writing of impact case studies. This researcher went on to raises questions around early career researchers (ECRs), and how they might measure impact in the long-game context. A question was also asked about how to measure impact or write an impact story in emergent fields such as Virtual Reality (VR), and the difficulties in assessing how current work in VR 
might impact industry in the future because it is an emergent technology. Panellists also felt that culture is an important consideration, because impact is more than money and commercialisation and should include cultural and social dimensions. But this raises another important question: how might we measure cultural impacts?

A researcher drawing on their experience as an ECR and a manager felt that great care needed to be exercised about the advice given to colleagues in screen production research, because as a field the area does not have the historical credentialing of more established disciplines. This researcher spoke about the bind of mentoring staff in terms of personal career strategies and institutional pressures. They felt that we needed to grow people at both the individual level as well as the institutional, and that the priorities of the individual should not be overlooked. They noted that we also need to be mindful about the way individual institutions take on, interpret and mandate impact and engagement, and set up reward structures for academics. It was felt strongly that people need to be supported at a discipline level as well as at an institutional level.

Another researcher spoke about the shift to multidisciplinary collaborations because of the new engagement and impact agenda. This researcher posed a question what might a pathway to impact look like? - and summarised the Canadian way of looking at impact as a potential answer to this question. Cultural changes and cultural/public discourses are used as measures of impact for research in Canada, where connections with NGOs and possible partners are a part of impact narratives. The Interrupters documentary was cited as one example of an impact pathway narrative for the ASPERA community. In it, measures are diverse and compound, and social impact is important. Industry connections are vital. In the Canadian research landscape, they 
see co-supervision of $\mathrm{PhDs}$ with industry partners as measures for pathways to impact, along with co-authorship of articles with industry partners.

Another researcher spoke about ARC Linkage Grant experiences with regard to the establishment of the Filmmaking Research Network with the UK's University of Sussex. A survey was conducted earlier in 2017, and there were some points that were fed into the symposium panel discussion by this researcher to inform the discussion. In brief, the survey had 168 participants who were academics and $\mathrm{PhD}$ researchers: $74 \%$ from the UK, 17\% from Australia and 9\% from the USA. 198 research film case studies were offered up for the register, and these included budgets and ERA/REF research statements. The survey found an average of roughly 6 written outputs per film, which included academic and popular press. Case studies will be written up based on ERA/REF research statements and could be relevant here. But what about these films as having an impact on the general community?

This researcher suggested we can look at films that are accepted into film festivals as examples of broader community reach and engagement. They cited The Act of Killing (2012) as a key case study because it received public research funding (AHRC), was nominated for an Oscar in 2014, and shifted public discourse around the historical events depicted in the film, which was subsequently included in a report containing a condemnation of the genocide by the National Committee for Human Rights, which recommended a truth and reconciliation process. This film had the same kind of social impact as the examples provided from the Canadian context. This researcher also spoke about the Australian film Orchids: My Intersex Adventure, by Phoebe Hart, which received several awards as well as having academic impact. It was noted that the narrative around the film as research with impact was not clear, though, and that these awards were indicators for engagement (and esteem) rather than impact. 
Another researcher saw engagement happening before impact, and that engagement is necessary for impact. This researcher argued that these definitions and distinctions are of vital importance for our discipline, because engagement is really easy for us, yet engagement is not impact and so we have to think about what that means. To support this argument further, the researcher also spoke about how keen Oppenheimer (director of The Act of Killing) was to distance himself from the academy, continually claiming that his film was about creative practice rather than research, even though he had received AHRC funding to make it. This researcher restated that impact has a long lead time, and the kinds of impact tale we can tell are limited because of this, even if we can easily access engagement metrics. A big issue for this discipline is that universities are more likely to choose other areas to support impact building, because they have a longer research history.

Another researcher observed that a film can be an output for a research project in areas that have nothing to do with screen production as a discipline and identified that there is a danger of filmmaking becoming instrumental as a means of engagement - or worse, service - for other disciplines, especially those with longer lineages. This was suggested by the researcher as an area we should think about as a potential for the discipline, especially given the power of screen production to create artefacts that can create deep engagement.

One researcher saw engagement as being measured through funding: monies coming in from external organisations to support research, and so monies coming from people not associated with research institutions. In this way, engagement is mostly concerned with dollars, whereas impact is about making a change in the broader community. This researcher is concerned that, as screen practitioners, we will end up as service providers to other researchers; that they will come to us asking, 'Can you make 
us a film?' In scenarios such as this, we need to carefully balance the invitation to participate with the needs of our own research questions and knowledge pursuits.

There was a common concern among the audience members to raise the profile of non-traditional outputs, and they wanted to know if impact might be a way to do this. One researcher sees the impact agenda as a key opportunity, and claims that institutions are recognising this quite rapidly, but that this also raises challenges regarding research quality and the differences between creative practice and creative practice as research. This researcher referred to previous discussions within the ASPERA community about the dangers of retrofitting a creative work as research: screen practitioner-researchers need to be clear and rigorous about the way in which they deal with creative practice as research. Another researcher agreed that there is a great need to be vigilant about quality, and that, for example, it is not just about new technology making something research ipso facto (e.g., the temptation to focus on technological developments in VR research). For this researcher, research needs to be framed clearly and informed by theoretical perspectives from the outset.

Another question from the floor asked whether engagement and impact will increase the profile of practice-based research. One of the researchers addressed this question by speaking about the 'newness' of practice-based research in screen production, feeling that the language was still being worked out. Screen production research is more than being service providers, where academics in screen production can collaborate with other academics in transdisciplinary teams to evidence parts of their research with film, and that more arguments for film as a scholarly research output need to be mounted. Another of the panel members extended the argument being made here by referring to case studies of films that were put forward for the engagement and impact pilot, which were not made by screen production researchers but were included 
in the 19 FoR code as they were regarded as the mode of delivery for the claimed impact.

The point about not all research having to be impactful was reiterated at this stage in the discussion. It was hoped that as evaluation processes mature, cultural impacts as well as social impact measures will be used. Another researcher responded with the understanding that cultural impacts contribute to an archive of shared knowledge, and that social impact includes peers who draw on the same body of cultural knowledge. Furthermore, academics have many different social networks and they need to explain what they do across these different networks. This is where the impact lies.

Overall, then, researchers see impact and engagement from different perspectives and value it variously. A clear picture of what engagement and impact looks like is yet to emerge and coalesce into a shared understanding that can then be put into practice.

\section{Perspectives from research leaders}

This panel comprised research leaders who, collectively, represent heads of school, current and former associate deans of research, and those identified by the sector as leading researchers, based on publications, funded projects, national and international reputation, etc. Between them they have worked as institution-based ERA and REF leaders, reviewers of ERA and REF submissions, and importantly here, have been instrumental in submitting university case studies of engagement and impact, both in Australia and the UK. In short, this panel comprised those who have done and are doing the work of evaluating research, engagement and impact, and who have been tasked by their various institutions to develop strategies for success. Examples of prompt questions provided to the panel include: 
- How important is the engagement and impact agenda in the grand scheme of things?

- Should everyone be involved in engagement and impact, or should it be channelled to specific areas and project types?

- Is this a total research culture shift, and if so, how are universities dealing with it so far?

- Do universities have processes for facilitating and mapping engagement and industry? If so, what works and what needs to be improved?

- Do you see screen production as having its own engagement and impact narratives, or is it better placed to assist other disciplines?

- Can you see any correlations or contradictions between screen production research outputs and the work of engagement and impact?

One research leader mentioned that one 'benefit' for Australia is that the UK has already undertaken a lot of work to define and assess research engagement and impact, so there is a basis from which to work. That said, there was a sense from this research leader that we are still in a period of consolidation and nuancing - do we really know what it is yet? - and also that perhaps the term 'impact' is reductive; might value be a better concept to try and both understand and encourage participation in this space? In terms of some of the challenges presented to us, in the context of yet another thing academics have to do, we can start by asking, do we really know what it means to engage with industry? What is industry and university collaboration? How do we cocreate research questions and projects? Do we have the skills to do it; indeed, does everyone have the appetite to do it? Building capacity is key, and might we think about developing a critical mass of people (i.e., not everyone) who can do this work and who, collectively, are enough to generate a good return? In other words, is engagement and 
impact for everyone? Should it be more 'calculated' and strategic, rather than universities trying to get buy-in from all their staff? Relatedly, and as presented on by representatives from the ARC at RMIT University on 12th February 2018, if there is, as yet, no research income attached to this exercise, and with only one case study put forward per 2-digit FoR code, how much should this really be driving academic behaviour?

This research leader instilled the fact that engagement and impact demands training, experience and opportunities to develop the skills required to engage with industry, and the sector needs to invest in this. They felt strongly that an engagement/impact narrative can be pulled together well by the right team of people, but only if the right seeds have been sown initially, and if over time, appropriate evidence for deep engagement and impact is collated.

Drawing on their experience of working on an institution's strategy for mapping existing engagement and impact, and looking to build it, another research leader reported that the picture for engagement was strong - there were a lot of partnerships happening - but impact was a much smaller picture and hard to pin down. There were less obvious, tangible impact outcomes, and so the question 'does this lead back to engagement?' arose. To clarify, this research leader said that while engagement was viewed as being strong, there was a lack of documentation as evidence of it. If there is a lack of documentation and reflection on the process of engagement, does that mean that impact can also suffer? Are researchers perhaps not being encouraged to think about the work they are doing, so that there becomes an impetus to follow through with engagement activities that might lead to impact?

This research leader also spoke of the large number of junior researchers at their university, so there were fewer impact stories to draw from. This is the case with 
members of the ASPERA community too, and so how might we solve this in the short term? It was suggested that universities and disciplines might think creatively about engaging with industry / end users, such as having research Chairs and $\mathrm{PhD}$ cosupervisors to build immediate connections.

This research leader then drew on their own example of a potential impact case study, to talk through some of the complexities in documenting and framing the research value. First, given the large size of the team involved in the project, it was hard to demonstrate who the impact was a result of; furthermore, given the ARC's impact rating being partly based on the support of the university to generate that impact, it was also deemed difficult to make a claim for their university having had a significant claim in assisting with the impact. This raises an important question of the ARC's criteria for an impact rating: why are they equally interested in the support of the university and the impact itself? Is this a sign about where they want universities to go; about what the ‘core business' or research should be?

Second, the engagement and impact of the 10-year international project was clearly very big, but the research leader reported that the university was cautious about using it as a case study because of the small part it had played in the project. The ARC's 2018 rules do allow institutions to make claims for projects that they shared with other institutions, but will this be perceived as less 'prestigious' than a project that sits exclusively or predominantly with that institution? This is another factor for universities to consider, and in this context, will it affect how institutions conceive of the projects they want to support? Or is there genuine merit in partnering with other institutions and sharing impact stories if required?

A third research leader noted that in this new climate, there is a real need for excellent research leaders/managers to ensure that not only is good research undertaken, 
but also that KPIs such as engagement and impact are met. These KPIs were said to be a hard balance to strike, which is why skilled and strategic people are needed to ensure that everything works well. For ASPERA in particular, there is still a lot of work to be done to build the research capacity of the discipline, let alone move into the engagement and impact climate with confidence. This research leader impressed upon us the need to think strategically about the ways in which we can do this at the same time as starting to participate in the engagement and impact agenda. We cannot get left behind, but at the same time, we need to care for the discipline. After all, it is disciplines that drive research collaborations.

This research leader posed another important question: are we creating knowledge within/for creative outputs, or are we creating knowledge that is associated with the practice of making creative outputs? In other words, there appear to be different agendas within disciplines such as ASPERA, which have a direct effect on the potential for engagement and impact. For example, if new knowledge is to be found within a creative artefact, what kind of impact narrative might this follow? Who is the knowledge/work for? If, however, creative practice is used as a method within a broader research project, perhaps more concerned with the social sciences or cultural studies (see Hope 2016), is this creative work a method for engagement that stands a 'better' chance of having demonstrable impact? And in cases such as this, what is the research question and what knowledge is being created?

The question of terminology was also raised by this research leader, namely: is 'knowledge transfer', which was used in the UK for a long time, a better way to describe engagement and impact, one that a) combines the two aspects into one expression, and b) sounds, and thus encourages work that is, more organic and participatory, as opposed to top-down, KPI-driven as measured? This research leader 
also called for a nuancing of the definitions and raised the point that sometimes we create insights and understandings, not necessarily 'knowledge'. This does, however, raise the question: whose understanding? Insights for whom? Can we justify personal insights and understandings in the current climate? Should the government really be funding this as research?

The core messages from this panel raise questions around why we do research, who we want to engage with, and how we might engage. They also encourage researchers to think about how they might bring end users into the research design, from the questions that need to be asked (which might not be the same as the questions that academics would ask), to the ways in which research might be conducted and disseminated (who will come to research events; what is in it for them?). Engagement and impact can raise very useful epistemological questions and re-orient a researcher's understanding of their job. A key point made by the first research leader was that we the ASPERA community - should benefit from this, given the type of work we do, so let us get on with it and reap the rewards.

\section{Implications for screen production research}

Here we pull together the key ideas raised at the symposium and analyse what they mean for the screen production research community broadly, and the ASPERA community specifically. While not purporting to offer a comprehensive audit of everything we believe screen production researchers need to consider, we focus on what are, perhaps, the most pressing considerations for the discipline.

\section{How poised is the ASPERA community for engagement and impact?}

Before we think about leading engagement and impact initiatives, do we need to take stock of where we are with research more generally? Where are we performing well, 
and where do we still need to develop? Do we, for example, have enough leading researchers and/or research leaders in the discipline to make sense of the current agenda and mentor one another? As outlined in the introduction to this paper, ASPERA - and, arguably, screen production researchers internationally - are still trying to plant their feet in the academy. There are relatively few practitioner-researchers who are able to work equally creatively and critically; who can make substantial creative works and write a suite of high-quality journal articles, for example. While not all screen production researchers will want to do this, to foster research excellence across both modes - then with the added requirement of engagement and impact - will require us to develop strong research teams and leaders who can mentor others. In the meantime, of course, we can work closely with those from more established and successful 'sister' practice-based disciplines, such as creative writing, design and the performing arts.

These capacity considerations aside, we should also think about the positive things the discipline has to offer that might leverage engagement and impact opportunities. For example, is there something inherently collaborative about screen production that can draw us together, either within the discipline or with those outside of it? Are there skills and knowledge we already possess that might be of value to other researchers and management? One idea here might be the potential of screen producers to interpret and visualise complex data and information for wide understanding, whether that be in the form of a documentary, essay film or fictionalised scenario.

We do, however, have to be wary here that this type of work might be service for other discipline areas and research questions (see Wilson 2018, p. 77); but it could be a good start and might also leverage exciting co-publication possibilities. Some members of the ASPERA community reported that they already working in this way and enjoy the collaborative nature of a large research project, where - as might be the 
case in industry - they are set a working brief that involves the production of one or more films on a given topic.

\section{Will screen production researchers have to work differently?}

As observed in relation to the perspectives presented by the industry panel, there are research hotspots that have been identified by industry practitioners where they see academics could add value. At present these hotspots tend to lie outside the areas of screen production research that are the focus of the ASPERA community. In developing the relationships between industry and academic research, there may be definite implications for methods and methodology, but there will also need to be innovations in how projects are framed to incorporate multiple research approaches to answer complex questions. As with previous goals around research capacity building within the discipline, resources and effort will need to be put into identifying and developing the points of value in screen production research and how it can be applied in industry contexts. Choices around methods and methodology will need to be thought about through the lens of what impact might look like, rather than just focusing on research excellence through outputs.

At the core of all this thinking, we argue, is the fundamental question: what kinds of impact are there anyway? Accordingly, where do we want to create change? Impact can be framed in many ways, including social, cultural, technological, practice, knowledge base, treatments, rituals and processes. Innovations in research approach will need to keep step with areas of intended practice. While a discussion of building pathways to impact in practice-based methodologies is outside the scope of this paper, a speculative mapping of ways to build impact in via the initial research design is a consideration that is deserving of further attention. 


\section{Is there still a place for blue-sky research and passion projects?}

The current structure of the engagement and impact audit, where each institution submits one impact case study per two-digit FoR code, allows space for other researchers to still engage in blue sky research as long as the criteria of research excellence and quality are met. It is possible to foresee, however, that future trends may follow the trajectory of the current funding agenda, and as a member of the researchers' panel observed, individual institutions may see this as a prompt to introduce award structures that shift the focus for increasing numbers of academics towards research objectives of engagement and impact. However, depending on the industrial experience of the researcher, there will potentially be overlaps between blue sky research and the kind of applied research that could change workplace practices, which can be seen as highly impactful.

It must be noted that, at the time of writing, there is still no clear consensus as to what impact looks like in screen production research. There are many varying interpretations of what the ARC definition might mean when it plays out within the context of different discipline areas. Even a cursory look at some of the UK's REF impact case studies reveals a wide range of claims, from those projects that have influenced changes in the law, to animation techniques that have been taken up by industry, to projects where the evidence of impact is local community and family members say that they liked a film.

The area of impact is also a highly contested space in the sense that discipline areas will be competing for research funds, and will increasingly have to justify projects in terms of benefits and impacts. In such a landscape, where will blue sky projects sit? While the 'real world' applications for such research projects are often not immediately apparent, impact can be an emergent and at times an accidental outcome, and the nature 
of potential impacts may take some time before they cohere or are revealed. This argues for resources to still be made available to speculative, blue sky projects.

There is potential for more focused sharing of the outcomes of blue sky screen production research projects with craft guilds (such as the Australian Screen Editors and the Australia Directors' Guild) and other industry associations. As previously highlighted, many screen production researchers are already engaging in creative practice research that responds to questions prompted by industry developments. By the nature of past connections from having worked in industry, or an in depth awareness borne from years of close analysis of industrial trends, the outcomes of creative practice research can be of direct relevance to guild members and broader practitioners who may not have the time or infrastructure to engage in such detailed investigations.

Engagement with these expert end-users could be one way to build pathways to impact that satisfy both the desire on the part of academics to conduct research that excites them and the push to find user-value for such research. It would also be one strategy to address the apparent invisibility and poor understanding of creative practice research, and demonstrate its relevance to industry.

\section{What strategies might ASPERA develop to encourage participation in engagement and impact?}

With the potential for strong engagement and impact case studies to grow and bring added prestige to the screen production research discipline, there is a clear motivation for ASPERA to play an agenda setting role in engagement and impact as well as working to build researcher participation. Methodological choices that are likely to play a significant part in seeding impact need to be built in at the start of a project. For example, there is the potential to bring in industry leaders to work on projects and/or supervise $\mathrm{PhD}$ projects, as well as instituting industry fellows and chairs. A 
complicating factor here is the typical requirement to have a $\mathrm{PhD}$ in order to supervise a $\mathrm{PhD}$, and the same with a Masters by Research. There are, however, many industry professionals with doctorates, and in this case, there could be value in exploring research collaborations beyond the role of a co-supervisor. ASPERA could thus provide model frameworks for structuring such relationships and play a role in setting standards for assessing the quality of outputs that result from this kind of engagement activity.

Additionally, might ASPERA run its own engagement and impact 'mini evaluation' exercise, as a way to both socialise the agenda and mentor others in writing case studies and offering assessments? Something similar to this is suggested in the Journal of Media Practice's review of the 2014 REF, as part of a suite of actions that could 'help enormously to minimise the time and anxiety that often accompanies the preparation of practice outputs' (Adams and McDougall 2015, p. 102). With a focus on creative practice works, such a mini evaluation could provide ASPERA, and the universities of its community members, with examples of best practice, case studies for further research, and a sense of the gaps where professional development might occur, either within the peak body or at universities.

\section{Conclusion}

While there is both a nervousness and a lack of understanding about engagement and impact in the Australian screen production sector, new and exciting opportunities will invariably arise in this new era of research. For example, those who seek active collaboration with disciplines such as health, law and economics could find themselves collaborating in strong research teams and see their research track records grow exponentially. Transdisciplinary teams have their own unique challenges and these are outside of the scope of this paper; however, we propose that screen production researchers need to ensure that working in transdisciplinary collaborations will advance 
screen production research as well as other disciplines, and this in itself is an area worthy of future research.

For those screen production researchers who are passionate about enhancing their own discipline, there might also be ways to reorient or reframe what they already do in order to gain external acknowledgement. This type of work, such as developing techniques for using VR in new settings and contexts, might then lead to invitations to collaborate with others or to share new knowledge with industry guilds and practitioners. Thus, while the behaviour of some researchers might change in response to this new agenda, that of others might not so much change, but rather breed a determination to ask new screen production research questions that take the discipline itself in new directions.

As highlighted in this article, taking an eye off disciplinary excellence can lead to creative practice researchers being at risk of becoming subsumed into other disciplines; becoming 'service providers' to other research agendas. While this can clearly be fruitful terrain for many researchers, it is also important for screen production research to be recognised as having value in and of itself. In the coming months and years, then, it will be important for the ASPERA community to work out what it is really good at, and in turn, what it can offer to others. Do we run the risk of jumping the gun too soon?

Either way, engagement and impact is here and it is likely to stay. New researchers are likely to be more attuned to what it means with shifts in the research training offered by universities, formally and informally via doctoral programs, internships and skills development initiatives. For existing researchers, the learning curve might be steeper, but it could also be more career rewarding. Let us end by considering this message from the ARC, which reminds us all that when devising 
research projects, we would do well to ask ourselves why we are doing them in the first place:

Experience from overseas - for example in the United Kingdom's Research Excellence Framework (REF) — has shown that the assessment of the impacts of research beyond academia creates incentives for universities and researchers to focus more strongly on the wider benefits when planning and conducting their research (Australian Research Council 2017, p. 6).

\section{List of references}

Adams, J. and McDougall, J. (2015). Editorial: Revisiting the evidence: practice submissions to the REF. Journal of Media Practice, 16(2), 97-107.

ASPERA (2017). Screen production research reporting: An ASPERA scoping project. Available at: http://www.aspera.org.au/wp-content/uploads/ASPERA_SP ResearchScoping_Report_FINAL_2017a_sm.pdf [accessed 22 February 2018].

Australian Research Council (2017). Engagement and impact assessment pilot: Review. Available at: http://www.arc.gov.au/engagement-and-impact-assessment [accessed 22 February 2018].

Barton, S. (2017). Defiant Lives [Feature Film]. Wr./Dir. Sarah Barton. Australia, 90 mins.

Beker, M. (2013). The Screenwriter Activist: Writing Social Issues Movies. New York: Routledge.

Chatto, C.B. and Das, A. (2014). Assessing the social impact of issues-focused documentaries: Research methods and future considerations. Center For Media and Social Impact. Washington, DC. Available at: http://www.cmsimpact.org/media- 
impact/related-materials/documents/assessing- social-impact-issues-focuseddocumentaries [accessed 15 November 2017].

Friesen, T. (2014). Canadian Impact Media Research Report. Available at:

https://inspiritfoundation.org/wp-

content/uploads/2017/03/canadian_impact_media_report.pdf [accessed 15 November 2017].

Galloway, S. (2009). Theory-based evaluation and the social impact of the arts. Cultural Trends, 18(2), 125-148.

Gibson, R. (2018). 'Foreword: Cognitive Two-Steps.' In: Screen production research: Creative practice as a mode of enquiry, edited by Craig Batty and Susan Kerrigan. London: Palgrave Macmillan, v-xiii.

Hinton, T. (2014). The power of hindsight: Evidence-driven reflections on impactful higher education research. Available at:

http://conference.herdsa.org.au/2014/pdf/4g(i).pdf [accessed 10 March 2018].

Manyozo, L. (2017). Communicating with development with communities. London: Routledge.

NESA website ref https://syllabus.nesa.nsw.edu.au/english/english-k10/english-key/

Watt, J. (2015). Report of the review of research policy and funding arrangements.

Canberra, Australia: Department of Education and Training. Available at:

https://www.education.gov.au/review-research-policy-and-funding-arrangements-0 [accessed 1 March 2017].

Webb, J. (2017). Screen production research engagement and impact symposium: 
Keynote address. Available at: http://www.aspera.org.au/research/screen-productionresearch-engagement-and-impact-symposium-keynote-address/ [accessed 23 February 2018].

Wilson, J. (2018). Artists in the university: Positioning artistic research in higher education. Singapore: Springer Nature. 